\title{
Mechanical Behaviors of Kaolin Powder Filler Polypropylene/Low Density Polyethylene Blends
}

\author{
Pham Thi Hong Nga* \\ Hochiminh City University of Technology and Education, Mechanical Engineering Faculty, Metal and Technology Department, \\ 70000, Vietnam
}

\begin{tabular}{l} 
A R T I C L E I N F O \\
\hline Article history: \\
Received: 23 June, 2019 \\
Accepted: 14 August, 2019 \\
Online: 23 August, 2019 \\
\hline Keywords: \\
Kaolin \\
PP/LDPE blend \\
Tensile strength \\
\hline
\end{tabular}

\begin{abstract}
A B S T R A C T
In this work, kaolin powder was filled in PP/LDPE blend as the filler with the amount from 0 to $14 \mathrm{wt} \%$. The ratio of PP/LDPE was fixed as 50/50 in all the experiments. The tensile strength, impact strength, and hardness were investigated in according with ASTM. The results showed that the tensile strength of PP/LDPE blend was slightly increased, the hardness was also increased while the impact strength was decreased in the presence of kaolin powder as the filler from 0 to $14 \mathrm{wt} \%$.
\end{abstract}

\section{Introduction}

Mixing of two or more different polymers is now considered as an economical way to the development of new polymers [1]. Low-density polyethylene (LDPE) has good mechanical properties, withstand high temperatures, easy to handle so they have wide applications in the industry [2]. PP also has some characteristics such as high stiffness, low plasticity, but these characteristics making the PP structure are easily destroyed, so the PP applications are also limited [3]. Therefore, to improve the mechanical properties of PP, and to create new materials with appropriate characteristics, LDPE has been studied and combined with PP to form PP/LDPE blend composition. Although, PP is similar to LDPE, they are different in some significant properties, PP/LDPE blends produce immiscible form.

The recent work of L.F. Kadhim et al [4], who investigated the mixures of PP and LDPE in the following percentages of LDPE by weight: $25,50,75$. The results showing that the addition of LDPE to PP, have been declined the tensile strength, flexural strength, flexural modulus and hardness while the density improved LDPE as a result of the nature of LDPE is more flexible than PP. However, they are still only used for business purposes. One of the most important ways of polymer mixing is the incorporation of fillers to enhance mechanical toughness. As fillers, kaolin, $\mathrm{CaCO}_{3}$, and talc are used along with engineering polymers to reduce both the production costs and to improve the properties. PP/LDPE/filler blends have been studied by different researchers from different

\footnotetext{
*Pham Thi Hong Nga, Email: hongnga@hcmute.edu.vn
}

aspects [5-7]. In types of filler, kaolin has certain advantages to improve the characteristics of PP/LDPE blend composition. It changes bonding between polymer blends to enhance bonding between blends and to create a chemical bond course between the blends of polymers and kaolin, therefore to improve the mechanical properties of PP/LDPE blends [8-11]. Many studies have so far been done on investigating PP/LDPE/Kaolin composites. According to S.N. Mustafa et al, the addition of kaolin powder to the PP/LDPE blend leads to increase the tensile strength, modulus of elasticity, shore-D hardness and impact strength and it decreases the elongation at break [12]. Water absorption of the $\mathrm{PP} / \mathrm{LDPE} /$ kaolin composites behaves as function of time has also been investigated, and it increases by increasing immersion time for the same filler content, while the absorbed amount of water increases, by increasing the wt.\% of kaolin at constant immersion time.

Table 1: Compositions of the samples (wt.\%)

\begin{tabular}{|l|l|l|l|l|l|}
\hline \multirow{3}{*}{ Material } & \multicolumn{4}{|l|}{ Components (wt.\%) } \\
\cline { 2 - 6 } & \multicolumn{3}{|l|}{ Samples } \\
\cline { 2 - 6 } & S1 & S2 & S3 & S4 & S5 \\
\hline 50\% PP and 50\% PE & 100 & 97 & 95 & 90 & 86 \\
\hline Kaolin & 0 & 3 & 5 & 10 & 14 \\
\hline
\end{tabular}

\section{Experimental}

\subsection{Materials}

PP (LyondellBasell - Moplen HP500N, origin Saudi Arabia) and LDPE (SABIC - LDPE 4024, origin Saudi Arabia) supplied 
by Thuan Thang Plastics Co., Ltd. Kaolin $\left(\mathrm{Al}_{2} \mathrm{Si}_{2} \mathrm{O}_{5}(\mathrm{OH})_{4}\right)$ were collected from Tran Tien Chemical Company. Kaolin has a particle size of $44 \mu \mathrm{m}$, specific gravity $2.58-2.63 \mathrm{~g} / \mathrm{cm}^{3}$, and whiteness $89-93 \%$.

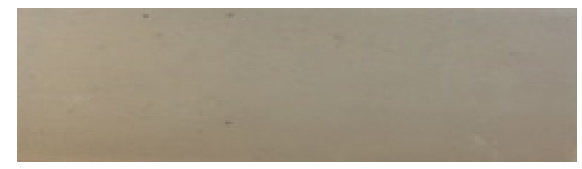

Figure 1: The sample after pressing

In the preparation of the blends, samples including PP/LDPE and kaolin were put into the mixer according to the ratios (Table 1). These composites are called as S1, S2, S3, S4 and S5. All compounds were prepared by using system of mixing and extruding machine Polylab OS - Haake (Germany). Basic parameters of the system are $20 \mathrm{~cm}^{3}$ sealed mixing chamber, the device extracts two screws $\mathrm{L} / \mathrm{D}=25, \mathrm{D}=16 \mathrm{~mm}$, one-screw extruder connected with sheet extrusion system $(0.2-1.2 \mathrm{~mm} x$ $100 \mathrm{~mm}$ ). Samples were mixed for $6 \sim 7$ minutes at a mixing temperature of $180^{\circ} \mathrm{C}$. After mixing, the sample are pressed to plates with the temperature of the tray at $180^{\circ} \mathrm{C}$. The pressing process was carried out for 5 minutes and then cooled for 20 minutes. All of these blends were prepared as samples keeping the PP/LDPE (50/50) ratio constant. The sample after pressing is 50 $\mathrm{x} 145 \mathrm{~mm}$ and the thickness is $3.2 \mathrm{~mm}$ (Figure 1). The samples are then cut to the size of the tensile test specimen and the impact strength test specimen.

\subsection{Experimental methods}

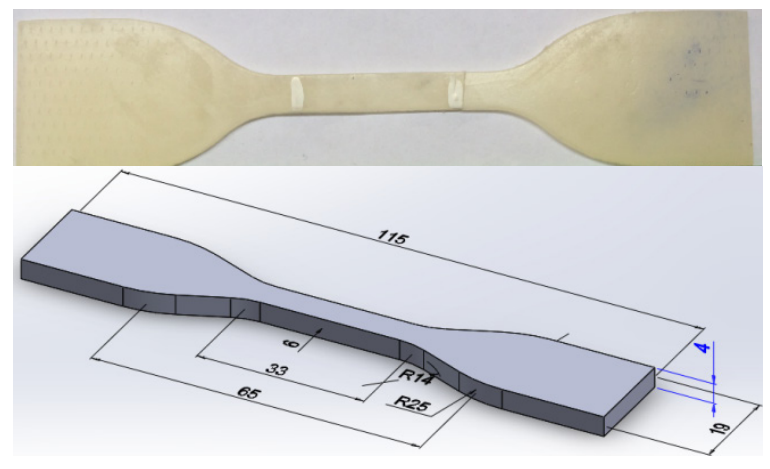

Figure 2: Tensile strength of test sample

The tensile properties were determined following the ASTM D638-02 procedure, using type IV test specimen dimensions (Figure 2) and using a Universal testing machine (Shimadzu Autograph AG-X Plus 20kN). This machine has the longitudinal stretch with high resolution camera $(1.8 \mu \mathrm{m})$ and does not touch sample test. The crosshead speed was set at $50 \mathrm{~mm} / \mathrm{min}$ at room temperature and four samples were tested for each composition.

The Izod impact strength was investigated according to ASTM D256. The composites were produced as $3.2 \times 12.7 \times 64 \mathrm{~mm}$ and a triangular with an angle of 450 , the radius of a glider at the bottom of the groove is $r=0.25 \mathrm{~mm}$, shown in Figure 3. The experiment was performed with $5 \mathrm{~J}$ collision energy and about $60 \mathrm{~mm}$ in length at room temperature. Five samples were tested for each composition.

Shore D scale was used to determine the hardness values of all samples. The tests were carried out the SHORE D Durometer www.astesj.com
DESIK. The durometer measures hardness by determining the depth of penetration into the material under test. The dial was graduated from 0-100 with a pointer sweep of $265^{\circ}$. Five samples of each formulation were tested and the average values were reported. The Fracture surface of each specimen in bending strength test was observed by Scanning Electron Microscope (HITACHI S - high resolution - 4800) with acceleration $5.0 \mathrm{kV}$. The surface of the samples used for SEM all was platinumsputtered with a conductive layer before observation.

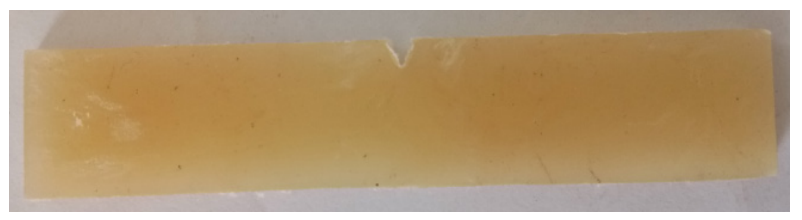

Figure 3: Sample measurement of impact resistance

\section{Result}

\subsection{Tensile strength}

Figure 4 shows the stress-strain curve when pulling of the samples. Table 2 shows the tensile strength results of each sample group. From the data in Table 2, a chart showing the average value of the tensile strength of each sample group was established (Figure 5). The results of elongation at break in Figure 4 indicating the sample S4 at 3.50532\% has the lowest elongation at break and sample S5 has the highest elongation at break (4.50412\%). These values are an indication of the ductility of PP/LDPE/Kaolin blends. The higher value of elongation is showing the blend more ductile.

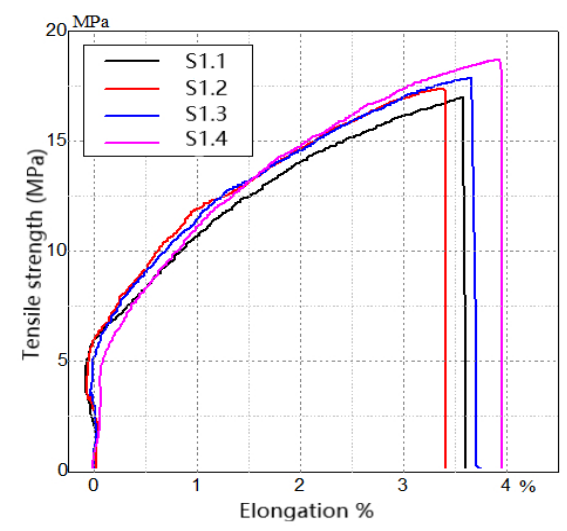

a) Sample S1 (0 wt.\% kaolin content)

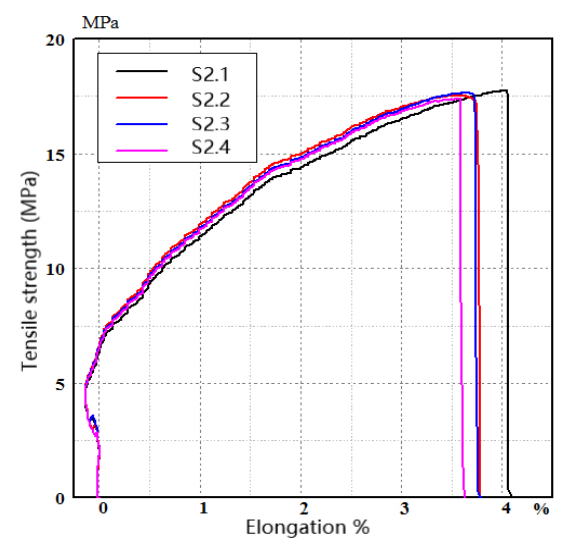

b) Sample S2 (3 wt.\% kaolin content) 


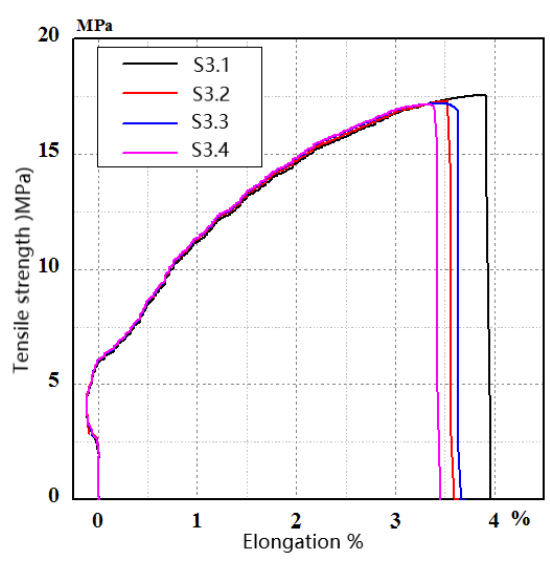

c) Sample S3 (5 wt.\% kaolin content)

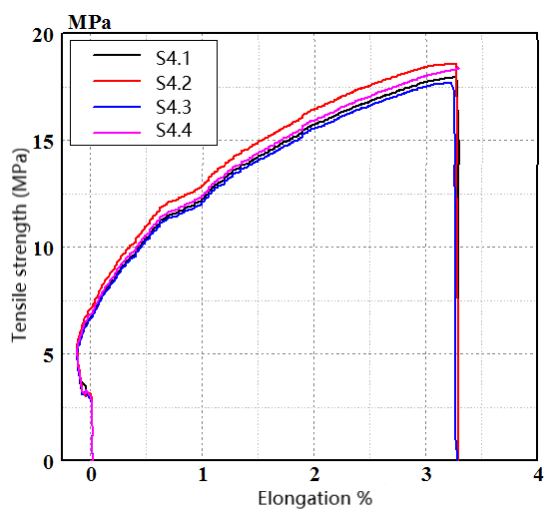

d) Sample S4 (10 wt.\% kaolin content)

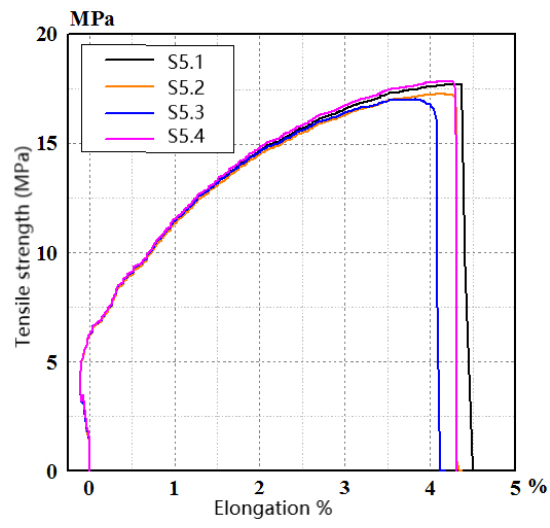

e) Sample S5 (14 wt.\% kaolin content)

Figure 4: Stress-strain curve when pulling of the samples

Table 2: Results of tensile testing of samples

\begin{tabular}{|l|ll|ll|}
\hline Sample & $\begin{array}{l}\text { Average Tensile strength } \\
(\mathrm{MPa})\end{array}$ & $\begin{array}{l}\text { Average Strain } \\
(\%)\end{array}$ & \\
\hline S1 & 17.4904 & & 3.69081 & \\
\hline S2 & 17.5919 & & 4.39359 & \\
\hline S3 & 17.3139 & & 3.68962 & \\
\hline S4 & 18.1919 & & 3.50532 & \\
\hline S5 & 17.4757 & & 4.50412 & \\
\hline
\end{tabular}

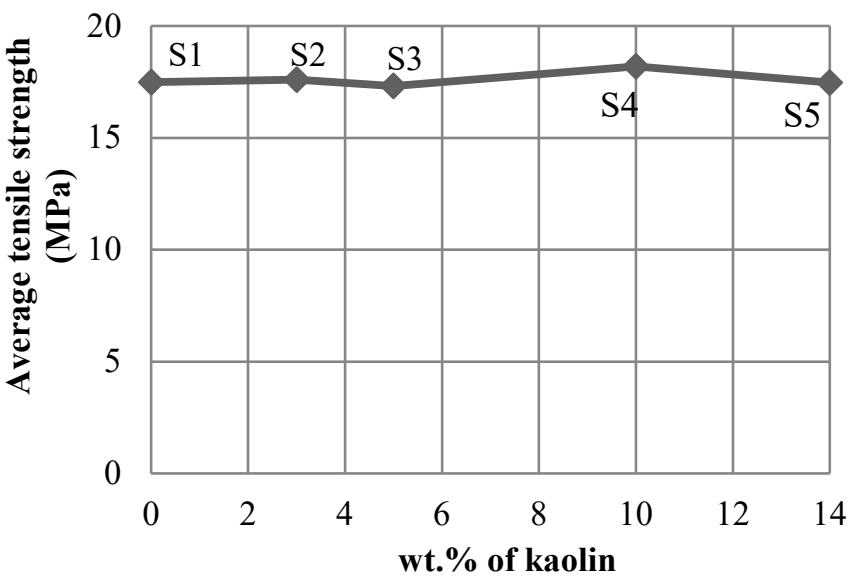

Figure 5: Average tensile strength of the samples

Figure 5 shows the average tensile results of the five samples. The tensile strength of PP/LDPE/Kaolin blends is increased with the addition of kaolin from $3 \%$ to $10 \mathrm{wt} . \%$. $10 \%$ kaolin addition will have significant increase up to $18.1919 \mathrm{MPa}$ comparing with the sample without kaolin (17.4904 MPa) while the higher amount of $14 \%$ kaolin didn't seem to have better significant improvements. Tensile strength is an indication of the stiffness of a material. The adding of kaolin filler into the PP/LDPE matrix improves the stiffness of the blends. In the sample S4, the tensile strength is highest due to the distribution of filler on the PP/LDPE composite substrate surface that creates a hierarchical crystalline process between bridges. With sample $\mathrm{S} 3$, the tensile strength is lowest $(17.3139 \mathrm{MPa})$ due to the large concentration of fillers in a given region which affects the crystallization. However, if there is more filler content in the polymer matrix will lead to the formation of the micro-filler and uneven kaolin particle size, and induces the difficulty of achieving a filling of filler in the PP/LDPE composite matrix forming holes [2]. This result influences the stress concentration at the boundary of the particle/ matrix and leads to a decreasing in particle/ matrix interactions. Therefore, it has a small effect on tensile strength [9].

\subsection{Impact strength}

The impact properties of PP/LDPE/Kaolin blends are summarized in Table 3 and Figure 6. As shown in the figure, the impact strength of PP/LDPE/Kaolin blends were decreased when increasing kaolin filler, $1.68806 \mathrm{~kJ} / \mathrm{m}^{2}$ for sample $\mathrm{S} 1,1.54280$ $\mathrm{kJ} / \mathrm{m}^{2}$ for sample S2, $1.49422 \mathrm{~kJ} / \mathrm{m}^{2}$ for sample $\mathrm{S} 3,1.46986 \mathrm{~kJ} / \mathrm{m}^{2}$ for sample S4 and $1.30425 \mathrm{~kJ} / \mathrm{m}^{2}$ for sample S5. The reason is that PP/LDPE blends produce immiscible form because of the low interfacial adhesion. However, the immiscibility is good enough to preserve the good features of each polymer components of the blend. For example the impact strength of a polymer cannot be improved significantly by adding fillers with it [4]. In addition, in the mixture of PP/LDPE, kaolin acts as an evenly distribute effect in the PP/LDPE matrix and it will affect the chemical bonds between the kaolin and the PP/LDPE mixture [10]. For this reason, increasing kaolin filler content probably increased the level of stress concentration in the PP/LDPE composites with the resultant decrease in impact strength [9]. 
Table 3: Results of impact strength testing of samples

\begin{tabular}{|l|l|}
\hline Sample & Average impact strength $\left(\mathrm{kJ} / \mathrm{m}^{2}\right)$ \\
\hline S1 & 1.68806 \\
\hline S2 & 1.54280 \\
\hline S3 & 1.49422 \\
\hline S4 & 1.46986 \\
\hline S5 & 1.30425 \\
\hline
\end{tabular}

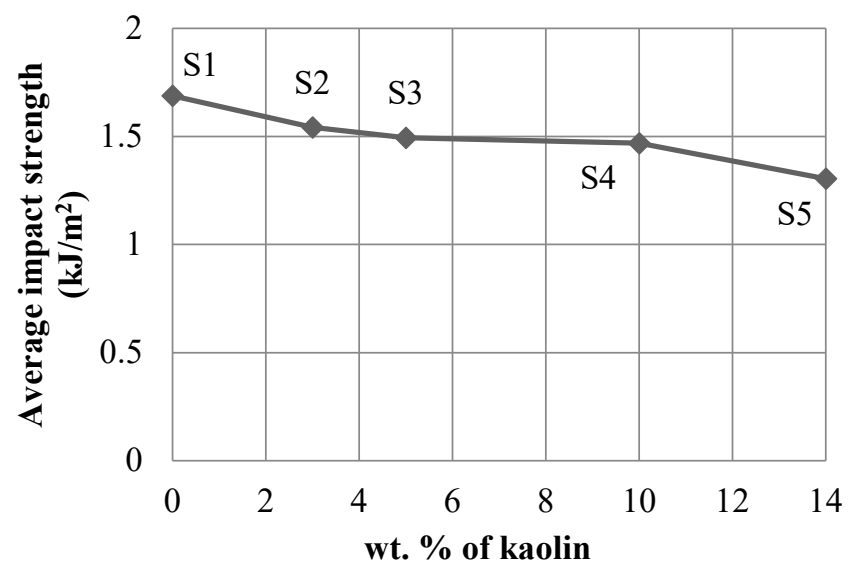

Figure 6: Impact strength of the samples

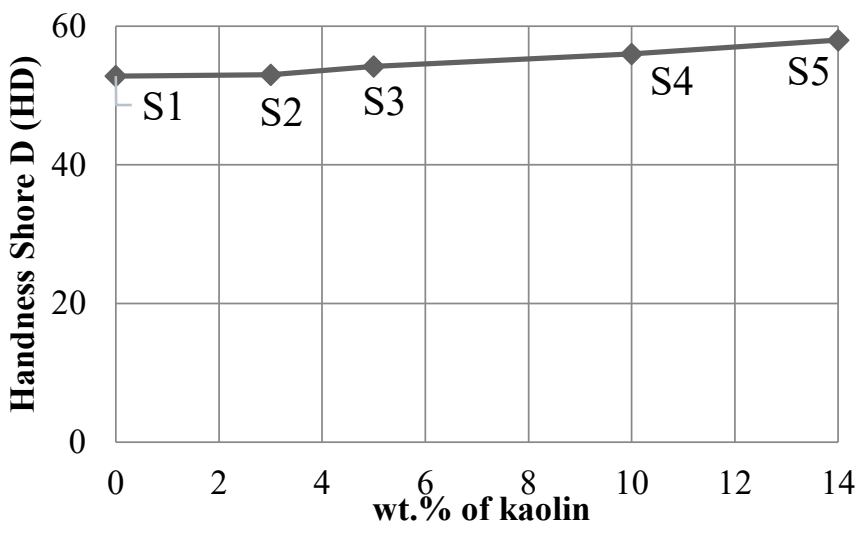

Figure 7: Hardness of the samples

\subsection{Hardness}

The hardness of PP/LDPE/Kaolin blends are showed in Figure 7. The hardness of PP/LDPE/Kaolin blends were all higher than the unfilled sample. The tests of hardness properties can evaluate the effects of adding kaolin fillers in PP/LDPE. It is evident from Figure 7 that a significant increase 52.8, 53, 54.2, 56 and 58 Shore $\mathrm{D}$ with adding $3,5,10,14 \%$ kaolin, respectively. This is attributed to the fact that this filler acts as a reinforcing filler. Incorporation of the filler into the polymer matrix enhanced the stiffness of the material. The increase in hardness is due to the structure of the composite occurring in most reinforcement fillers. The higher the percentage of the filler incorporated, the harder the material, and the more rigid it becomes [10]. In composite PP/LDPE/kaolin, the mixture is characterized by the dispersion of vertical kaolin crystals in conjunction with the direction lines. When kaolin is combined with a thermoplastic mixture, it increases the hardness and produces concentrated stress, this also contributes to the reduction of the impact strength when added with kaolin filler [8].

\subsection{Microstructure}

To better analyze the mechanical properties of the PP/LDPE/Kaolin mixture. SEM micrographs for the $\mathrm{PP} / \mathrm{LDPE} / \mathrm{Kaolin}$ blends were conducted. The results were shown in Figure 8. The sample $\mathrm{S} 1$ can see the pictures of the spherulites of PP in LDPE. PP is presumed to be the dispersed phase due to its high viscosity and elasticity. The PP spherulites size is coarse and could be easily distinguished. The reason is that PP and PE are compatible but only partially miscible. The PP/LDPE pairs tend to separate into two liquid phases. During the process of PP crystallization, the growth of PP spherulites in a "homogeneous" melt of a mixture of PE and PP will involve the propagating PP spherulite front encountering domains of PE melt [11]. When adding kaolin, PP spherulites is finer. The increasing the content of kaolin, the finer of the PP spherulites also increases.

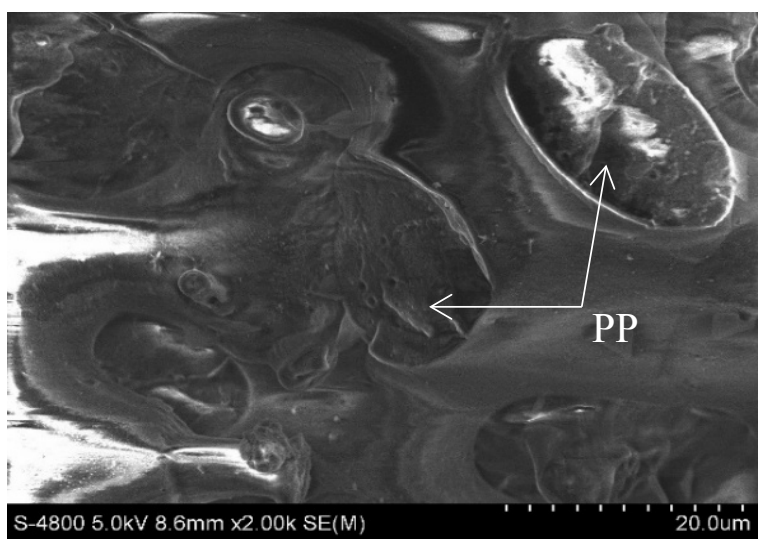

a) Sample S1 (0 wt.\% kaolin content)

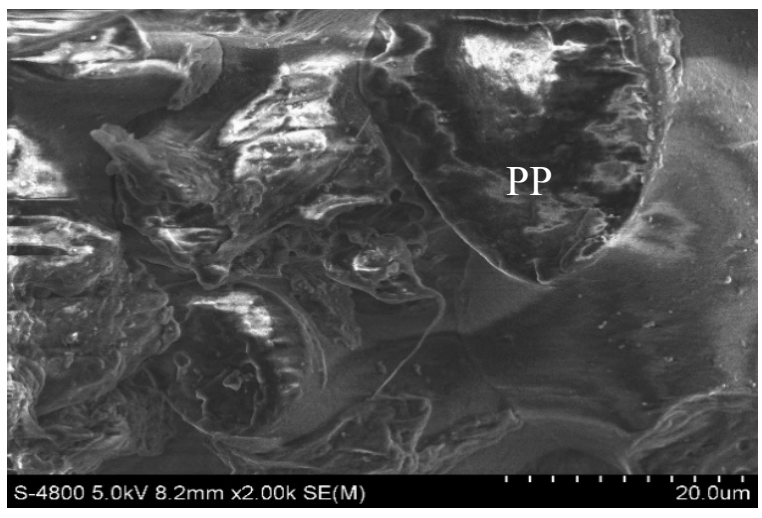

b) Sample S2 (3 wt.\% kaolin content)

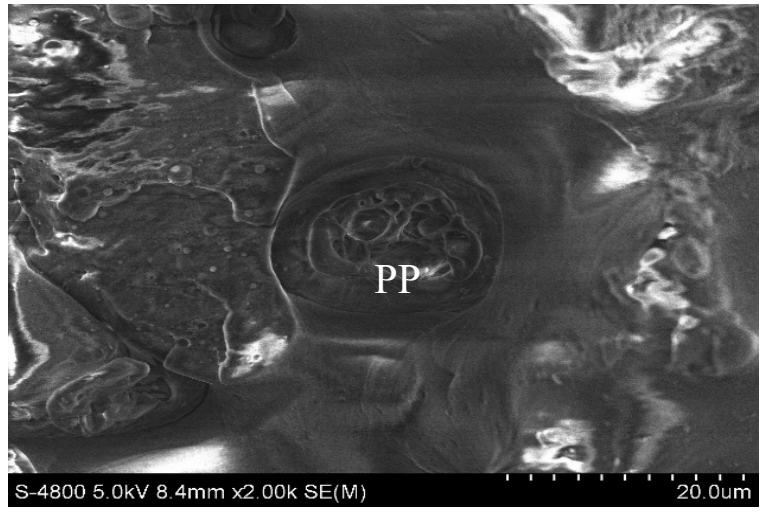

c) Sample S3 (5 wt.\% kaolin content) 


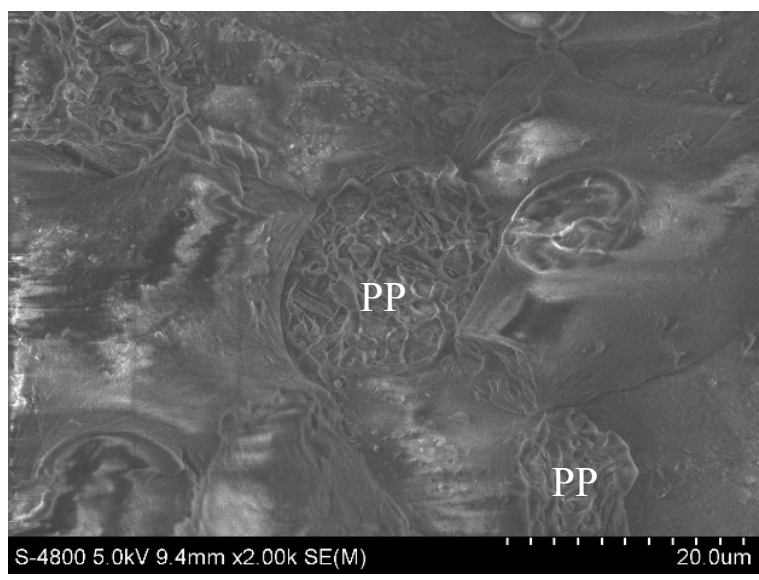

d) Sample S4 (10 wt.\% kaolin content)

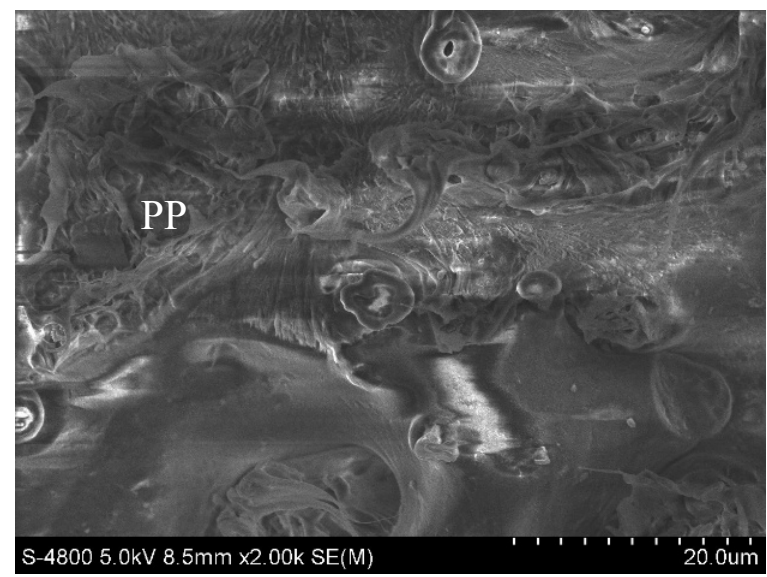

e) Sample S5 (14 wt.\% kaolin content)

Figure 8: Surface collapse microstructure

\section{Conclusion}

From the above results, it was found that The tensile strength of PP/LDPE/Kaolin blends is increased with the addition of kaolin from $3 \%$ to 10 wt. $\%$, but higher contents of kaolin $14 \%$ decreased the tensile strength.

When adding kaolin with PP/LDPE blend to increase the hardness but at the same time, it creates concentrated stress that reduces the impact strength. Adding kaolin to the PP/LDPE blend composition reduced the impact strength from $1.68806 \mathrm{~kJ} / \mathrm{m}^{2}$ to $1.30425 \mathrm{~kJ} / \mathrm{m}^{2}$ when increasing kaolin filler. On the contrary, the hardness of the PP/LDPE/Kaolin blends are increased by increasing the content of kaolin from 52.8 Shore D in samples without kaolin fillers to 58 Shore D in sample adding $14 \mathrm{wt} . \%$ kaolin filler.

\section{Conflict of Interest}

The authors declare no conflict of interest.

\section{Acknowledgment}

We are acknowledging HCMC University of Technology and Education, Dong Nhan Phat Co., Ltd and Material Testing Laboratory (HCMUTE). They gave me an opportunity to join in their team, accessed to the laboratory and research machines.
Without their appreciated support it would not be possible to conduct this research.

\section{References}

[1] P. T. H. Nga; T. N. Thien, "Effect of Kaolin on the Mechanical Property of Polypropylene/Low Density Polyethylene Blend", 4th International Conference on Green Technology and Sustainable Development (GTSD), HCM City, Vietnam, 2018. DOI: 10.1109/GTSD.2018.8595576.

[2] M. Guessoum, S. Nekkaa, F. Fenouillot-Rimlinger, N. Haddaoui, "Effects of Kaolin Surface Treatments on the Thermomechanical Properties and on the egradation of Polypropylene", Hindawi Publishing Corporation International Journal of Polymer Science, 2012, 1-9, 2012. http://dx.doi.org/10.1155/2012/549154.

[3] H. Essabir, M. O. Bensalah, D. Rodrigue, D. Rodrigue, R. Bouhfid, A. e. k. Qaiss, "A comparison between bio- and mineral calcium carbonate on the properties of polypropylene composites", Construction and Building Materials, $\quad 134, \quad 549-555, \quad 2017$. https://doi.org/10.1016/j.conbuildmat.2016.12.199.

[4] L. F. Kadhim, Z. F. Kadhim, "Studying The Properties of PP/LDPE polymer blend", Journal of Babylon University/ Engineering Sciences, 25(1), 193-201, 2017.

[5] M.S. Hassanien, A.I. Seedahmed, "Mechanical and rheological properties of polypropylene (PP)/ linear low density polyethylene (LLDPE) blend filled with talc and calcium carbonate compositions", Int J Eng Sci Res Technol, 4(1), 383-387, 2015.

[6] K. Sirin, M. Balcan, F. Doğan, The Influence of Filler Component on Mechanical Properties and Thermal Analysis of PP-LDPE and PPLDPE/DAP Ternary Composites: Polypropylene, InTech China, 2012.

[7] M. Thomas, A. D. Kamble, N. John, "A Study on the Influence of Compatibilizer and Mica Filler on the Properties of Thermoplastic Polyurethane/Polyolefins Blends", Chem Sci Trans., 2(1), 181-191, 2013. DOI: $10.7598 /$ cst2013.286.

[8] E.M. Khalaf, S.A. Awad, "Improvement of Mechanical and Water Absorbance Properties of Low-Density Polyethylene (LDPE) by using White Kaolin Powder (WK)", J. Adv. Chem. Sci., 3(1), 426-427, 2017.

[9] A. Mallika, A. K. Barik, B. Pal, "Comparative studies on physico-mechanical properties of compositematerials of low density polyethylene and raw/calcined kaolin", Journal of Asian Ceramic Societies, 3, 212-216, 2015. http://dx.doi.org/10.1016/j.jascer.2015.03.001.

[10] C. Onuoha, O.O. Onyemaobi, C.N. Anyakwo, G.C. Onuegbu, "Effect of filler loading and particle size on the mechanical properties of periwinkle shell filled recycled polypropylene composites", Am J Eng Res, 6(4), 72-79, 2017.

[11] R.A. Shanks, J. Li, L. Yu, "Polypropylene-polyethylene blend morphology controlled by time-temperature-miscibility", Polymer, 4(1), 2133-2139, 2000. https://doi.org/10.1016/S0032-3861(99)00399-7.

[12] S. N. Mustafa, "Effect of kaolin on the mechanical properties of polypropylene/ polyethylene composite material", Diyala Journal of Engineering Sciences, 5(2), 162-178, 2012. 